\title{
A rare cadaveric case of a duplicated internal thoracic artery
}

\author{
Harry Nanthakumar ${ }^{1}$, Joe Iwanaga ${ }^{1}$, Aaron S. Dumont ${ }^{1}$, R. Shane Tubbs ${ }^{1,2,3,4}$ \\ ${ }^{1}$ Department of Neurosurgery, Tulane Center for Clinical Neurosciences, Tulane University School of Medicine, New Orleans, LA, ${ }^{2}$ Department of \\ Structural and Cellular Biology, Tulane University School of Medicine, New Orleans, LA, ${ }^{3}$ Department of Neurosurgery and Ochsner Neuroscience \\ Institute, Ochsner Health System, New Orleans, LA, USA, ${ }^{4}$ Department of Anatomical Sciences, St. George’s University, St. George’s, Grenada, West \\ Indies
}

Abstract: The internal thoracic artery (ITA) arises from the subclavian artery and terminates as the musculophrenic and inferior epigastric arteries. During routine cadaveric dissection, an aberrant left ITA was discovered. A medial and a lateral branch of the ITA branched directly off the subclavian artery as opposed to bifurcating at the 6th or 7th intercostal space. To our knowledge, this is the first reported case of this particular ITA variation arising from the third part of the subclavian artery. Additionally, such a variant might also be considered a high bifurcation of the ITA. Our report examines this variation and its potential implications for coronary artery bypass grafts where the ITA is commonly used.

Key words: Mammary arteries, Subclavian artery, Coronary artery bypass

Received March 13, 2020; Revised May 20, 2020; Accepted June 5, 2020

\section{Introduction}

The internal thoracic artery (ITA) (internal mammary artery) is a branch of the subclavian artery that travels down the internal aspect of the anterior thoracic wall. Along its path, it gives branches that supply the thymus, breast, mediastinum and sternum [1]. At the 6th or 7th intercostal space it bifurcates and becomes the musculophrenic and superior epigastric arteries.

The ITA has become the vessel of choice for a coronary artery bypass graft (CABG) surgical intervention in multivessel coronary artery disease [2]. CABG is the most commonly performed cardiac surgery in the world. In the USA alone, there are 200,000 cases performed annually [3]. The ITA exhibits strong resistance to atherosclerosis build-up,

\section{Corresponding author:}

Joe Iwanaga (i)

Department of Neurosurgery, Tulane Center for Clinical Neurosciences, Tulane University School of Medicine, New Orleans, LA 70112, USA

E-mail: iwanagajoeca@gmail.com has minimal complications with its use, and has excellent post-operative success [4]. Specifically, grafting of the left ITA to, for example, the anterior interventricular artery is today, the gold standard.

In this case report, we describe an extremely rare case of a duplicated ITA. Such a variant could potentially impact using the ITA for CABG procedures.

\section{Case Report}

Duplicated left ITAs were found on the left side during a routine dissection of the fresh-frozen cadaver whose age at death was 78 years (Fig. 1). The ITA arose from the inferior aspect of the subclavian artery (the third part). Immediately after arising from the subclavian artery, the ITA bifurcated into two parts; medial and lateral branches. The medial branch descended and became the superior epigastric artery and the lateral branch became the musculophrenic artery. The musculophrenic artery anastomosed with the intercostal arteries. Both branches were less than $1.5 \mathrm{~mm}$ in diameter. No other variations were found in the dissected area. The right ITA did not show any similar anatomical variations.

\section{Copyright ( 2020 . Anatomy \& Cell Biology}

This is an Open Access article distributed under the terms of the Creative Commons Attribution Non-Commercial License (http://creativecommons.org/licenses/by-nc/4.0/) which permits unrestricted non-commercial use, distribution, and reproduction in any medium, provided the original work is properly cited. 


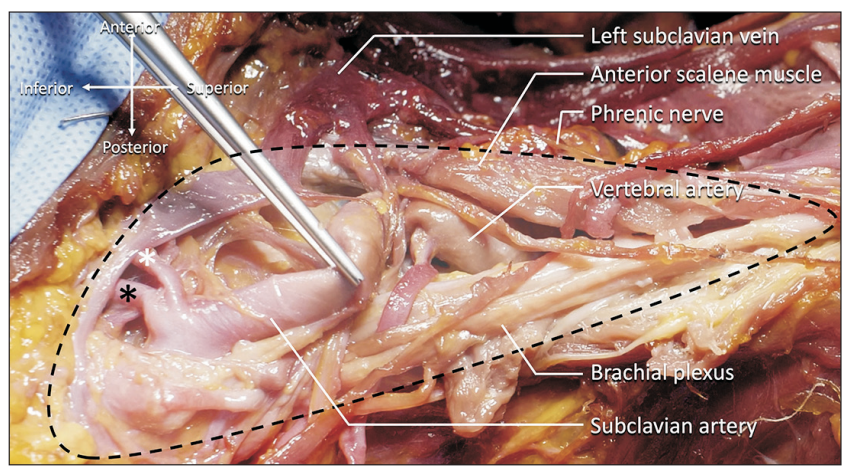

Fig. 1. Left scalene triangle (dotted line). Note the medial (white asterisk) and lateral (black asterisk) branches of the internal thoracic artery.

\section{Discussion}

The occurrence of anatomical variations of the ITAs that can affect surgical intervention vary but have been reported in the literature [5]. According to Lippert and Pabst [6], the ITA can arise from the thyrocervical trunk in $10 \%$ or from a common trunk of the suprascapular and inferior thyroid arteries in $8 \%$, the suprascapular artery in $4 \%$, the inferior thyroid artery in $1 \%$, the transverse cervical artery in $1 \%$, or the transverse cervical and suprascapular arteries in $1 \%$. In a case study by Burton and Ditkofsky [7], computed tomography showed bilateral aberrant internal thoracic arteries that bifurcated at the level of the pulmonary artery bifurcation. It was noted that such aberrations could complicate chest tube insertions and catheterizations.

Today, there are two common techniques used to harvest the ITA; skeletonized and pedicled harvesting. Skeletonized harvesting is utilized more often because of decreased sternal perfusion, post-operative pain and wound infections [8]. The posterior rectus sheath is separated from the sternum and costal cartilages and the internal thoracic veins are separated from the ITA [9]. Then dissection of the artery continues down toward the bifurcation of the vessel, avoiding the phrenic nerve and finally removing the artery from parasternal tissues and fascia down toward the 6th intercostal space. The resulting graft is about $3 \mathrm{~cm}$ longer than a pedicle graft and can have a larger conduit diameter and flow [10].

Another factor to consider is the significantly reduced diameter of both the medial and lateral branches of less than $1.5 \mathrm{~mm}$, compared to the average proximal, middle and distal ITA diameters of $2.28 \pm 0.45 \mathrm{~mm}, 2.34 \pm 0.39 \mathrm{~mm}$, and $2.12 \pm 0.38 \mathrm{~mm}$, respectively [11]. Zhang et al. [12] measured the average anterior interventricular artery diameter as 3.92 $\mathrm{mm}$ at its origin and $2.1 \mathrm{~mm}$ at its end. Thus, even if a graft in a case such as ours were enough, the small diameter of the aberrant ITA and its subsequent flow rate would possibly be inadequate to properly profuse the coronary arteries if used for CABG. Murray et al. [13] reported an incidence of the duplicated ITA $1 \%$. However, location of the bifurcation or diameter (most proximal part) of each branch was not mentioned in the literature.

This case has also shown the ITA arising from the third part of the subclavian artery. Only $0.5 \%$ to $0.83 \%$ of all cases are reported to have the ITA originating from the third part $[14,15]$. Embryologically, the ITA develop from longitudinal arterial channel of the intersegmented anastomoses. During caudal shifting of the aorta, abnormal connections between the longitudinal channel (ITA) and subclavian artery might have occurred [15].

In conclusion, based on this report, this variant ITA would be a poor option for CABG surgery due to its small size. Additionally, such a variant might also be considered a high bifurcation of the ITA. Surgeons should be aware of such variations and be prepared to use alternatives such as great saphenous vein and radial artery grafts for CABG procedures.

\section{ORCID}

Harry Nanthakumar:

https://orcid.org/0000-0002-3618-1507

Joe Iwanaga: https://orcid.org/0000-0002-8502-7952

Aaron S. Dumont: https://orcid.org/0000-0002-8077-8992

R. Shane Tubbs: https://orcid.org/0000-0003-1317-1047

\section{Author Contributions}

Conceptualization: JI, ASD, RST. Data acquisition: JI, RST. Data analysis or interpretation: HN, JI. Drafting of the manuscript: HN, JI. Critical revision of the manuscript: ASD, RST. Approval of the final version of the manuscript: all authors.

\section{Conflicts of Interest}

No potential conflict of interest relevant to this article was reported. 


\section{References}

1. Shahoud JS, Kerndt CC, Burns B. Anatomy, thorax, internal mammary (Internal Thoracic) arteries [Internet]. Treasure Island, FL: StatPearls Publishing; 2020 [cited 2020 Apr 13]. Available from: https://www.ncbi.nlm.nih.gov/books/NBK537337/.

2. Sabik JF 3rd, Lytle BW, Blackstone EH, Houghtaling PL, Cosgrove DM. Comparison of saphenous vein and internal thoracic artery graft patency by coronary system. Ann Thorac Surg 2005;79:544-51.

3. Yim D, Wong WYE, Fan KS, Harky A. Internal mammary harvesting: techniques and evidence from the literature. J Card Surg 2020;35:860-7.

4. Otsuka F, Yahagi K, Sakakura K, Virmani R. Why is the mammary artery so special and what protects it from atherosclerosis? Ann Cardiothorac Surg 2013;2:519-26.

5. Sajja LR, Mannam G. Rare variants of internal thoracic artery in patients with coronary artery disease. Indian J Thorac Cardiovasc Surg 2009;25:68-70.

6. Lippert H, Pabst R. Arterial variations in man: classification and frequency. Munchen: J.F. Bergmann; 1985.

7. Burton KR, Ditkofsky N. Incidental discovery of a new and clinically important anatomic variant of the internal thoracic artery in a young male trauma patient. BMJ Case Rep 2018;2018:bcr2017222838.

8. Josephraj G, Muthukumar M, Rani P, Karthikeyan B, Anandan H. Comparative study of pedicled versus skeletonized left internal mammary artery graft in coronary artery bypass graft surgery. Int J Sci Stud 2017;5:224-7.

9. Vo A, Nguyen T, Nguyen D. Left internal mammary artery harvesting: the skeletonization technique. CTSNet 2019 Feb 13 [Epub]. http://dx.doi.org/10.25373/ctsnet.7611560.

10. Behranwala AA, Raja SG, Dunning J. Is skeletonised internal mammary harvest better than pedicled internal mammary harvest for patients undergoing coronary artery bypass grafting? Interact Cardiovasc Thorac Surg 2005;4:577-82.

11. Masuda T, Matsuda Y, Tanimoto Y, Sakata K, Hayashi K, Kobayashi Y. Angiographic follow-up of internal thoracic artery for free bypass grafting. Ann Thorac Surg 1998;65:731-4.

12. Zhang LR, Xu DS, Liu XC, Wu XS, Ying YN, Dong Z, Sun FW, Yang PP, Li X. [Coronary artery lumen diameter and bifurcation angle derived from CT coronary angiographic image in healthy people]. Zhonghua Xin Xue Guan Bing Za Zhi 2011;39:1117-23. Chinese.

13. Murray AC, Rozen WM, Alonso-Burgos A, Ashton MW, Garcia-Tutor E, Whitaker IS. The anatomy and variations of the internal thoracic (internal mammary) artery and implications in autologous breast reconstruction: clinical anatomical study and literature review. Surg Radiol Anat 2012;34:159-65.

14. Krechowiecki A, Daniel B, Wiechowski S. Variation of the internal thoracic artery. Folia Morphol (Warsz) 1973;32:173-84.

15. Vorster W, du Plooy PT, Meiring JH. Abnormal origin of internal thoracic and vertebral arteries. Clin Anat 1998;11:33-7. 